Christina Bezari. 2017. "Emilia Serrano de Wilson: entre los salones literarios y los periódicos femeninos". Confluencia: Revista Hispánica de Cultura y Literatura, ISSN: 0888-6091, Vol. 33, No1, pp. 118-128. ${ }^{1}$

\title{
Resumen:
}

El presente artículo examina las interacciones que tuvieron lugar entre los salones literarios del siglo XIX en Europa y los periódicos fundados y dirigidos por mujeres. En primer lugar, se estudia la actividad periodística de Emilia Serrano de Wilson en París y su actividad como anfitriona y participante en varios salones. A continuación, se presentan extractos de su periódico La Caprichosa, que muestran la conexión de ésta con el mundo galante de su época. En los artículos que promueven la participación de la mujer en los salones subyace, además, un interés en favorecer la educación femenina, cuya importancia será también comentada. Por último, se analizan las diferentes estrategias de difusión de ideas que Serrano de Wilson llevó a cabo desde su periódico, así como las redes de comunicación que estableció con otras mujeres editoras y anfitrionas a lo largo de su vida. Estas redes superan los límites de la nación y adquieren un carácter transnacional de especial relevancia.

Palabras Clave: prensa femenina, salones literarios, La Caprichosa, redes, comunicación.

\begin{abstract}
:
This article examines the interactions that took place between the literary salons of the nineteenth century and the periodicals that were edited by women. In the first place, the article discusses Emilia Serrano de Wilson's activity as an editor and a salon hostess in Paris. Some examples excerpt from her periodical La Caprichosa will be presented in order to demonstrate the connection between the female press and the gallant world of the salons. Some of her articles that promote the participation of women in the intellectual circles of the salons also emphasize the importance of female education. This subject will be discussed thoroughly throughout the article. Finally, focus will be set on her dissemination strategies as well as on the communication networks that she established with other women editors and salon hostesses. These networks surpass the boundaries of the nation and acquire a transnational character of particular relevance.
\end{abstract}

Keywords: women-edited periodicals, literary salons, La Caprichosa, networks, communication.

\footnotetext{
${ }^{1}$ This work was supported by the H2020 European Research Council under the ERC Starting Grant agreement no. 639668 .
} 


\section{Emilia Serrano de Wilson: Entre los Salones Literarios y los Periódicos Femeninos}

"Nuestras amables compatriotas han lucido la gracia y la esbeltez de sus talles en los salones de las señoras de E. R. y G." escribe Emilia Serrano de Wilson en febrero de 1858 en su famoso periódico La Caprichosa, señalando así que la aparición de la mujer en la escena pública estuvo relacionada con el desarrollo de la sociabilidad que tuvo lugar en los salones de aquella época (Emilia Serrano de Wilson, 1858, 3). Efectivamente, Serrano de Wilson desempeñó diversos papeles en este mundo, adquiriendo con ello una proyección pública insólita. Con el objetivo de conseguir un cierto nivel de realización personal, asumió el papel de directora de periódicos, así como el papel de anfitriona de salones, haciéndose célebre no solamente en Europa sino también en México, Cuba y Perú1. Gracias a testimonios recientes, sabemos de la existencia de su salón en París donde estableció una poderosa red de colaboración con políticos y literatos franceses y españoles (Ortega, 2006). En estos salones, que se celebraban dos veces al mes, era habitual conversar sobre temas culturales, sociales y literarios. Quizás no fuera por pura casualidad que estas tres temáticas aparecieran también en las páginas de La Caprichosa, editada en París entre 1857 y 1860.

Entre los salones literarios de mujeres y la prensa femenina hubo diferentes vínculos de conexión, que sin embargo no han sido estudiados en profundidad. En realidad, son escasísimos los estudios comparativos de los periódicos editados por mujeres y los salones dirigidos por ellas (Ángeles Ezama Gil, 2014). No obstante, un estudio de estas características resultaría particularmente enriquecedor por dos razones fundamentales. Por un lado, los salones, cuya importancia analizaremos en este artículo, se sitúan ante una encrucijada decisiva, oscilando entre la esfera pública y la esfera privada. El estudio de este espacio semiprivado que representa el salón decimonónico nos ayudará a desarrollar una comprensión más profunda de la participación de la mujer en el diálogo intelectual de su época. Por otra parte, el estudio de los periódicos, que se sitúan en el ámbito de la esfera pública, nos permitirá comprender el impacto cultural que ejercieron las mujeres que desempeñaron la doble labor de editoras y anfitrionas de salones.

Antes de describir las relaciones que las mujeres editoras establecieron con el mundo galante de los salones, observaremos cuál era la relación que este mundo mantuvo con la prensa de la época. Ángeles Carmona González indica que los periódicos eran leídos y comentados por los asistentes de los salones: "un mismo periódico podía ser utilizado por muchos receptores a través de los salones" (Ángeles Carmona González 31). Su análisis resulta particularmente interesante, ya que afirma la existencia de un público lector limitado a estos espacios. Efectivamente, un ejemplar se podía leer en voz alta en un salón que contaba con muchos participantes. De esta manera, ellos se enteraban de la existencia del periódico y tenían la ocasión de solicitar una suscripción privada. Con el fin de aumentar las ventas de sus periódicos las mujeres editoras necesitaban tratar una amplia variedad de temas y dar a sus publicaciones un carácter más transnacional e interdisciplinario. Por esta razón, en las páginas 
de La Caprichosa se podían leer numerosas noticias comerciales, sociopolíticas y literarias no solamente sobre Francia sino también sobre otros países de América del Sur:

Gracias a que muy pronto van a estar establecidos los buques trasatlánticos, la Francia va a ser el centro natural del comercio de ambos mundos; pero el antiguo continente conoce muy poco el nuevo, y no sabe el inmenso partido que se puede sacar de él, porque hasta hoy no ha sido instituida ninguna publicación continuada. (Emilia Serrano de Wilson, Junio 1857, 8).

Las pocas mujeres que tuvieron la oportunidad de viajar, como fue el caso de Serrano de Wilson, solían comparar las costumbres de sus países de origen con las de otras culturas, para atraer así una mayor atención del público lector. El carácter transnacional del periódico implicaba una perpetua búsqueda de lo novedoso, y al mismo tiempo representaba el desafío del multiculturalismo, que marcó de manera decisiva la época moderna.

La existencia de una cultura de salón en París fue una base importante para las mujeres españolas que se establecieron en Francia en el siglo XIX. Con La Caprichosa, Serrano de Wilson sentó un novedoso precedente en una época en que la participación de la mujer española en los eventos culturales era todavía limitada. En muchas ocasiones informaba a su público de la existencia de bailes y salones literarios en la capital francesa: "Animado y del mejor tono, ha sido también el baile dado en casa de nuestra buena amiga la señora de P." (Emilia Serrano de Wilson, Marzo 1858, 2). Algunos años más tarde, Emilia Pardo Bazán otra mujer editora y anfitriona de salones que colaboró con Serrano de Wilson en la revista barcelonesa Álbum Salón, describió el salón parisino de Doña Isabel II la reina destronada de España: "En aquel palacio hospitalario de la avenida Kleber encontraban la reminiscencia de la patria, un españolismo sin afectación, una acogida llena de sencillez y de afecto" (Emilia Pardo Bazán, 1896, 37).

Este tipo de pasajes demuestran que los salones situados en París ofrecían la oportunidad única de crear una micro-comunidad de compatriotas españolas que constituían un público potencial de las publicaciones periódicas editadas por mujeres. Por lo tanto, es posible observar una fuerte conexión entre el tipo de sociabilidad femenina que se formó en los salones y aquella que se impulsaba desde ciertos periódicos de la época. La creación de redes de comunicación se hizo cada vez más importante para las mujeres editoras que intentaban difundir su trabajo y sus ideas entre el público. Por un lado, La Caprichosa y otras publicaciones periódicas se convirtieron gradualmente en fuentes a las que las lectoras podían acudir para obtener información sobre los salones ${ }^{2}$. Por otro, las mujeres editoras que asistieron a los salones podrían mantenerse en contacto con sus compatriotas para facilitar la difusión de sus publicaciones periódicas. Para llegar a una comprensión más profunda de los desafíos a los que Serrano de Wilson se enfrentó, es necesario un análisis minucioso del contenido de su periódico. 


\section{Las temáticas abordadas en La Caprichosa y el vínculo con los salones parisinos decimonónicos}

Publicado por la imprenta parisina Aubusson y Kugelmann, La Caprichosa era autodefinida como revista de buen tono y llevaba el subtítulo "Revista mensual de modas, literatura, música, salones y teatros". Parece que su primera suscriptora fue la emperatriz de Francia, Eugenia de Montijo (1826-1920), consorte de Napoleón III. Esta suscripción dio gran prestigio al periódico de Serrano de Wilson y ayudó a aumentar su público lector. El éxito de la publicación se debió, además, a la amplia difusión que alcanzó entre los españoles afincados en París y en otras grandes capitales europeas como Londres. Las entregas de la revista estaban compuestas con bella tipografía y en papel de alta calidad. Casi todas las entregas estaban acompañadas por una lámina policromada de figurines de moda femenina. Cada figurín estaba acompañado de una explicación que daba más información sobre el estilo y el origen de las prendas. La sección "Revista de la Moda", firmada por la propia Emilia Serrano de Wilson, abría cada entrega con una descripción detallada de las nuevas tendencias de la moda parisina. Además, recomendaba a sus lectoras no sólo de vestirse de manera elegante, sino también de asistir a conciertos de música clásica, obras de teatro y óperas. Desde su punto de vista, una mujer tenía que evolucionar tanto estéticamente como intelectualmente con el fin de combinar el buen gusto y el buen sentido.

Por este motivo, muy pronto la sección "Revista de la Moda" cambió de título, y pasó a llamarse "Revista de Modas, Salones y Teatros". Serrano de Wilson indicaba cuáles eran las prendas que estaban más de moda en los salones, y daba sugerencias sobre los modistos y las casas comerciales parisinas ${ }^{3}$. A veces describía los acontecimientos que tenían lugar en los cafés populares y en otros espacios de esparcimiento lúdico, como en los conciertos y en los teatros. También hacía menciones especiales a las señoras que integraban el entorno de sus salones, con un discurso que hacía hincapié en el hecho de que estos representaban una forma de sociabilidad que tenía como punto de materialización la mujer. En muchas ocasiones, enfatizaba el rol de las anfitrionas y expresaba su admiración por su buen gusto: "[...] la señora de P. había sabido reunir lo más elegante y distinguido en sus salones el lunes último" (Emilia Serrano de Wilson, Marzo 1858, 2). Por consiguiente, a través de su propia participación en los salones parisinos, Serrano de Wilson consiguió un estilo periodístico ágil, adornado con referencias culturales y literarias que le ayudaron a aumentar las ventas de su periódico.

Más allá de la esfera estética, que ocupaba un espacio central en las páginas de La Caprichosa, el periódico reflexionaba también otro tipo de conversaciones que solían surgir en los salones parisinos que frecuentaba Serrano de Wilson. Con este fin, el periódico contenía una columna regular bajo el título "Variedades" o "Costumbres" donde se ofrecía información sobre los acontecimientos socio-políticos que tuvieron lugar durante el régimen bonapartista de Napoleón III. Por lo general, esta columna estaba escrita por hombres, como Santiago Infante de Palacios o José Marco y no por Serrano de Wilson. El objetivo era proporcionar a las lectoras información valiosa y actualizada sobre una amplia variedad de temas políticos y sociales como las relaciones diplomáticas entre Francia y Alemania o la inauguración de avenidas en la capital francesa. De esta manera, las suscriptoras de $L a$ 
Caprichosa tenían la oportunidad de ponerse al día y renovar sus conocimientos sobre la actualidad. Esto les ayudaría a participar de manera más igualitaria en cualquiera de las conversaciones eruditas que tenían lugar en los salones literarios.

Las últimas páginas de La Caprichosa estaban dedicadas a la literatura y a la poesía. Esta sección del periódico fue la que logró más prestigio cultural, ya que los participantes de los salones parisinos conversaban frecuentemente sobre las novedades literarias acaecidas en Francia y en los diferentes países europeos (Martin-Fugier, 2003). Por ello, la última sección de La Caprichosa estaba principalmente dedicada a proporcionar información sobre la producción literaria más reciente en Francia y España. Serrano de Wilson insertó un buen número de composiciones en verso y en prosa, y algunas de ellas habían sido escritas en París. Las suscriptoras podían leer poemas de hombres y mujeres poetas como José Zorrilla y María del Pilar Sinués de Marco. También podían leer historias cortas escritas por autoras como Enriqueta Lozano de Vilchez, quien dirigió dos periódicos en Granada, o Ángela Grassi, que editó la famosa revista El Correo de la Moda desde 1865 hasta 1886. Por otra parte, Serrano de Wilson incluyó partes de sus propias traducciones de Un Viaje a la Luna de Alejandro Dumas (1857) y de los Cursos Informales de Literatura de Alphonse de Lamartine (18561869). También incluyó partes de la novela Pierre et Camille escrita por Alfred de Musset (1844) y traducida en español por Pilar Sinués.

Las conexiones transnacionales entre Francia y España se hicieron posibles no sólo por la participación de la élite española en los salones parisinos, sino también gracias al relieve que La Caprichosa dio a la traducción literaria. La sección que contenía esta información fue considerada como una parte clave de la originalidad del periódico. Con la inclusión de la traducción literaria en la sección de literatura y poesía, Serrano de Wilson creó un espacio público donde la literatura francesa podía ser leída y apreciada por un público lector hispanohablante. La literatura española estuvo también incluida. Las lectoras extranjeras que dominaban el español podían familiarizarse con autoras y poetas contemporáneas. De esta manera, Serrano de Wilson, así como otras mujeres editoras, emprendió el papel de la mediadora cultural entre su país de origen y otros países europeos, sobre todo Francia.

\section{Estrategias de difusión: Serrano de Wilson y sus colaboradoras}

Las estrategias editoriales de Serrano de Wilson tuvieron un doble efecto. Por un lado, se creó un espacio diverso y polifónico, prácticamente alejado del carácter doctrinal y moralizador tan característico de las revistas de mujeres de la época. Dentro de este espacio el buen tono, la sensualidad, el coqueteo y el poder femenino adquirían un valor positivo (Partzsch 2016: 301). Por otro lado, a través de la prensa periódica se concretó la dinámica social e intelectual de los salones. En sus diversos viajes entre España y Francia, Serrano de Wilson intentó tejer una red de conexiones, abriendo fructuosos diálogos con otras mujeres editoras que frecuentaban los salones literarios de Madrid. Un ejemplo característico es su colaboración estrecha con María del Pilar Sinués de Marco. A pesar de la trayectoria más cosmopolita de Serrano de Wilson, Pilar Sinués utilizó medios y estrategias similares para 
lograr sus objetivos y aspiraciones. Así, Pilar Sinués publicó un número significativo de sus poemas en diferentes números de La Caprichosa. Algunos años más tarde, editó sus propias revistas: El Ángel del Hogar (Madrid, 1864-1869) y Flores y Perlas (Madrid, 1883-1888). Íñigo Sánchez Llama indica que: "El Ángel del Hogar nos informa de la intensa vida social que su directora mantuvo en diferentes veladas y tertulias literarias" (Íñigo Sánchez Llama, 2000, 202). Como queda claro en el subtítulo de la revista, los salones también conocidos como tertulias en el mundo hispanohablante, eran un tema recurrente: El Ángel del Hogar: Revista semanal de literatura, educación, modas, teatros y salones.

En las páginas de su periódico, Pilar Sinués reivindicaba una mejor educación para las niñas, siempre pensada en un contexto doméstico. Aunque tenía una visión más conservadora que Serrano de Wilson sobre el papel de la mujer en la sociedad, siguió su ejemplo para hacer hincapié en los efectos positivos que los salones literarios tenían sobre la mujer. En muchos de sus artículos, Pilar Sinués explicaba de qué manera su revista trataba de instruir a las jóvenes para que tuvieran la oportunidad de acceder al elitista mundo de los salones: "[...] dar una educación elegante, y la joven, que la reciba, podrá brillar admirablemente en un salón" (María del Pilar Sinués de Marco, Diciembre 1865, 369). Además, subrayó otra función importante del salón decimonónico. Colette Rabaté nos informa que: "María del Pilar Sinués da su preferencia a estas "tertulias familiares", durante las cuales las muchachas pueden bordar y escuchar una obra de mérito interpretada por los labios de una persona amada" (193).

Por otro lado, los lugares de sociabilidad elitista como los salones franceses y las tertulias españolas ofrecían la posibilidad de conocer a una amplia variedad de personas, incluyendo potenciales cónyuges. Tanto Pilar Sinués como Serrano de Wilson mostraron una comprensión perceptiva de esta particular dimensión de los salones, y elaboraron este tema en las páginas de sus periódicos y revistas: "Ya que las tertulias son un "vivero de maridos" o un "bolsín del amor", muchas revistas y tratados dan consejos a las muchachas para que no cometan errores y saquen provecho de estas reuniones" (Colette Rabaté, 195). Una vez más, es posible trazar una fuerte conexión entre la prensa femenina y el mundo de los salones. Las editoras que disfrutaron del privilegio de participar en los círculos elitistas de los salones se hicieron buenas observadoras de sus singularidades y características. De este modo, fueron capaces de ofrecer a sus lectoras información concreta sobre las funciones y las cualidades de estas reuniones cultas. Hacia el final del siglo XIX, la creciente importancia de la prensa permitió al público lector entender el salón de una manera nueva. Fue entonces posible comprender su importancia a través del énfasis en los intercambios intelectuales y las redes transnacionales que fomentaba.

Por medio de las redes de comunicación con otras mujeres editoras y sobre todo por medio de la publicación de La Caprichosa, Serrano de Wilson pudo lograr una mediación cultural capaz de poner el mundo de habla española en contacto con nuevas costumbres, hábitos y visiones. Naturalmente, esta perspectiva fue complementada por la circulación de ideas de carácter transnacional, como por ejemplo la idea de la educación de la mujer. A este respecto, la contribución de otras mujeres periodistas, editoras, traductoras y anfitrionas de salones fue considerable. Emilia Pardo Bazán, Concepción Gimeno de Flaquer y Ángela 
Grassi constituyen ejemplos significativos de mujeres eruditas que defendieron en sus publicaciones la educación femenina. Es de especial interés subrayar que dichas mujeres, así como Serrano de Wilson, se sirvieron de la prensa periódica no sólo para articular sus ideas sino también para construir una plataforma pública que superara el círculo de sus conexiones inmediatas. Este espacio público que se creó estuvo asociado con el mundo culto de los salones literarios, que todavía mantuvieron un carácter semiprivado. En este punto, sería necesario tener en cuenta que los salones no tenían como fin educar al público general. La mayoría de ellos se dirigía a una élite ya instruida, que podía ser caracterizada como privilegiada. Por esta razón, el énfasis también se debe poner en los periódicos que tenían como fin informar, instruir y entretener al público lector. En este sentido, las funciones de los salones literarios y las de los periódicos pueden ser vistas como complementarias.

El doble papel que realizó Serrano de Wilson como anfitriona de salones y editora de periódicos le permitió atravesar la distancia entre lo privado y lo público, pasando de sus conexiones privadas e inmediatas a una red de conexiones más amplias. Quizás no sea de extrañar que en una época como la suya, sus publicaciones periódicas funcionaron como nudos en las redes de comunicación que estableció con gente que conoció, mayoritariamente, en los salones que frecuentó. Por citar un ejemplo, Serrano de Wilson describió con gran claridad los salones literarios de Juana Manuela Gorriti que frecuentó en Lima durante los años 1876-1877. Al describir su participación en los círculos intelectuales limeños, no dejó de mencionar que fueron estas veladas literarias que le ayudaron a establecer relaciones con otras mujeres periodistas y a consolidar su revista El Semanario del Pacífico (Lima, 1877-1878) (Emilia Serrano de Wilson, 1890, 79-87). En muchas ocasiones, subrayó la importancia para la mujer, europea o americana, de romper con su papel tradicional y pasar del ámbito cerrado del hogar a una forma de expresión pública favorecida en las páginas de los periódicos femeninos. Al modelo de la mujer pasiva yuxtapuso la mujer abierta, políticamente activa, tejedora de relaciones entre diferentes países y culturas. En este contexto, la prensa adquirió una influencia más grande que los salones, ya que empezó a constituir el medio de mayor difusión capaz de penetrar en los hogares y de formar opiniones públicas (Ortega, 111). Por esta razón, Serrano de Wilson tuvo que pasar del espacio elitista del salón al espacio más novedoso y prometedor de la prensa.

Para lograr una influencia más amplia, Serrano de Wilson tenía que abordar ante todo la espinosa cuestión de la educación de la mujer. Fue este el tema más importante de toda su obra periodística, y además marcó su trayectoria en el mundo de los salones literarios. En sus escritos de reflexión social y política evitaba la discusión sobre las clases sociales, con el fin de demostrar que la educación de la mujer constituye un valor amplio y universal. La falta de autonomía intelectual era principalmente una falta de acceso a derechos básicos como la escolarización de las jóvenes sobre todo en los países del sur de Europa. Elizabeth Sherman Swing explica que la universalización de la enseñanza primaria se inició en los países protestantes del norte de Europa en el siglo XVII, pero no se produjo, en algunos países del sur de Europa, hasta en la primera mitad del siglo XX (Elizabeth Sherman Swing, 2000, p.4). Como una consecuencia inmediata de esto, la participación de la mujer en el mundo laboral en el sur de Europa fue muy baja durante el siglo XIX, aunque las tentativas de fundar y 
dirigir periódicos eran generalmente numerosas, pero de corta duración. Convencida de los efectos positivos y enriquecedores de la educación y expresándose con mucha claridad y elocuencia, Serrano de Wilson enfatizó el rol educativo y profundamente transformador que la prensa femenina tuviera que desempeñar. Así, afirmó que:

Contra esta abyección [las mujeres que se consideran como cosas] no hay más remedio que la educación de la mujer; para que la educación sea un hecho es necesario que la prensa hable, y que donde quiera que haya un oído benévolo se oiga la voz de la ilustración de la mujer (Emilia Serrano de Wilson, 1911, 50).

En este contexto, resultaba fundamental disponer de medios de comunicación que fueran públicos (prensa) o privados (salones) ya que la mujer intelectual y activa tenía que educar y crear nuevos modos de expresión para las otras mujeres. Sobre este tema, Maida Watson nos informa que una función importante de la revista El Semanario del Pacífico era ofrecer a las escritoras la oportunidad de publicar sus ensayos y novelas (Maida Watson, 1992, p.51). Este fue también el caso de La Caprichosa que sirvió como plataforma de expresión para las mujeres autoras y poetas. En un período en el que las creaciones literarias femeninas casi no eran publicadas, este tipo de apoyo fue esencial, porque aseguró la aparición de la mujer en la escena pública. Además de proporcionar la oportunidad de desarrollar su escritura, Serrano de Wilson solía dar consejos a sus lectoras sobre las formas de participación en los salones parisinos y en las veladas literarias que tenían lugar en el otro lado del Atlántico. En su libro América y sus mujeres admitió que los salones constituyeron un mecanismo social que contribuyó de manera decisiva a la consolidación de "la hermandad de mujeres" (Leona Martín, 2002). Por consiguiente, el doble papel de editora y anfitriona de salones que Serrano de Wilson desempeñó en ambos lados del Atlántico le ayudó a aglutinar comunidades transnacionales, asegurando que el mensaje sobre la importancia universal de la educación llegase lo más lejos posible.

\section{Para concluir}

La vida errante y cosmopolita que tuvo Serrano de Wilson trazó una resistencia persistente a un paradigma monolingüe y monocultural. Sus periódicos, tanto La Caprichosa como El Semanario del Pacífico, abrieron sus páginas a una serie de traducciones, ensayos y poemas que trataban de modelar un gusto refinado, influyendo considerablemente en las nuevas tendencias que aparecieron en la época moderna. Tanto la parte literaria así como la parte social y noticiosa de sus periódicos pusieron a su público lector en contacto con las novedades de otros países europeos y americanos, superando los límites estrictos de la nación. El estudio comparado de los salones literarios y de las publicaciones periódicas nos ayuda a desarrollar una comprensión mucho más profunda de la manera en que se proyectaba la participación de la mujer en el diálogo público de su época. Por un lado, este estudio demuestra que las editoras tenían que pasar por el ámbito semiprivado de los salones con el fin de encontrar el público lector potencial para sus publicaciones. En este sentido, la participación en los salones se puede considerar como una estrategia de consolidación y de mayor difusión de los periódicos editados por mujeres. Por otro, los temas de interés social, 
cultural y literario que solían abordar los participantes de los salones aparecían de manera detallada en las páginas de los periódicos. De esta manera, las suscriptoras que no formaban parte de la élite intelectual y burguesa podían informarse sobre los temas tratados dentro de los salones y sobre las manifestaciones culturales que animaban las anfitrionas de aquella época. Así, las conversaciones privadas adquirieron un carácter público y pudieron ejercer un impacto más directo sobre un mayor público lector.

Las interacciones que tuvieron lugar entre el espacio privado de los salones y el espacio público de los periódicos revelan sus funciones esenciales y complementarias. Serrano de Wilson, así como otras mujeres editoras que frecuentaban los salones de las grandes capitales, trataban de buscar amenidades para informar, instruir y entretener a sus suscriptoras. La moda, los bailes y las creaciones literarias, así como los conciertos, las obras de teatro y los acontecimientos políticos y sociales eran temas que ambos espacios trataban de manera asidua. Estos temas cumplían una función primordial ya que enseñaban a las mujeres que la belleza espiritual era tan importante como la belleza física, y que ellas debían buscar tanto el crecimiento intelectual como el refinamiento estético. En este contexto, Pilar Sinués informaba a sus lectoras que una buena educación les ayudaría a "[...] desarrollar sus buenos instintos y extirpar los malos, si los tiene: le enseñará perfectamente la música, el dibujo, toda clase de labores de adorno y á hacer, á las mil maravillas, los honores del salón" (María del Pilar Sinués de Marco, Diciembre 1865). En este sentido, el salón constituía el lugar donde una mujer culta y refinada podía brillar y ser admirada por los círculos intelectuales de su época. El papel de los periódicos femeninos sería entonces forjar su educación y enseñarle valores y principios idóneos. De esta única manera, la mujer tendría acceso en el mundo galante de los salones, y podría participar en las conversaciones cultas y contribuir a la circulación de nuevas ideas y costumbres.

Entre todas estas consideraciones, el vínculo entre los salones literarios y la prensa decimonónica es de especial relevancia. En primer lugar, nos permite comprender la importancia de la mediación cultural y de la influencia intelectual que ejercieron ciertas mujeres en estos dos ámbitos. Es, pues, una piedra de toque para examinar de qué manera y hasta qué punto la participación de las mujeres en la arena pública fomentó la creación de redes transnacionales de comunicación. El ejemplo de Serrano de Wilson resulta característico. Una vez afincada en París mantuvo sus conexiones con otras mujeres editoras afincadas en España. Por consiguiente, María del Pilar Sinués, Ángela Grassi y Enriqueta Lozano de Vilchez colaboraron asiduamente a la publicación de La Caprichosa aprovechando la oportunidad de diseminar sus escritos en Francia. Por otra parte, las traducciones del francés que aparecieron en las páginas de La Caprichosa también contribuyeron en fortalecer los intercambios transnacionales entre el mundo francófono y el mundo hispanohablante. En 1895, cuando Serrano de Wilson se regresó a Barcelona después de una serie de largos viajes por los países de América del Sur, publicó unas semblanzas de mujeres ilustres en la prestigiosa revista barcelonesa Ilustración Artística. Con el fin de ampliar los conocimientos de los lectores europeos sobre las personalidades hispanoamericanas, Serrano de Wilson dio a su público lector la oportunidad de familiarizarse con las escritoras argentinas Juana Manuela 
Gorriti y Alvina van Praet de Sala, a las que conoció personalmente en los salones literarios de Lima y de Buenos Aires.

La magnitud y el dinamismo de las redes de comunicación que se crearon gracias a la mediación femenina tuvieron como resultado el surgimiento de un nuevo paradigma de multiculturalismo que marcó el siglo XIX de manera definitiva. Los viajes a otros países y continentes, la incansable actividad periodística, la extensa labor de traducción así como la participación en los salones literarios de la época constituyen factores que han podido cambiar el estado de la cuestión de la contribución de la mujer en la consolidación y el desarrollo de una sociedad moderna. Sería una falta no mencionar que el estudio comparativo de los periódicos dirigidos por mujeres y de los salones literarios permite una comprensión completa del cambio estructural en la posición de la mujer del espacio cerrado de su hogar al espacio dinámico y fértil de la arena pública. Dicho estudio es capaz de revelar numerosos intercambios y colaboraciones entre mujeres que fundaron, fueron propietarias o dirigieron salones y periódicos a pesar de que se hayan caído en el olvido. Por supuesto, las nuevas perspectivas de investigación que se abren tienen que ver con el papel de la educación femenina y con la consolidación de las redes de colaboración no sólo entre los países europeos sino también entre Europa y América Latina. Serrano de Wilson habló de dichas perspectivas con admirable agudeza y perspicacia:

El progreso, la civilización, el desarrollo intelectual de un pueblo, se revela por el grado de ilustración de la mujer. Veamos Chile y la Argentina, y el Perú y Colombia, y sobre todo el Norte América; estudiemos sus antecedentes, y ellos nos dirán que aquellas sociedades no llegaron al grado plausible que hoy tienen, hasta que no se dio más extensa y profunda educación a la mujer (Emilia Serrano de Wilson, 1890, 409)

\section{NOTAS}

${ }^{1}$ Emilia Serrano de Wilson además de ser editora de La Caprichosa, fue también autora de un gran número de novelas, obras en verso y trabajos biográficos publicados en París, Madrid, Barcelona, México y La Habana. También colaboró en decenas de revistas y periódicos. Fundó y dirigió asimismo: El Eco hispano-americano (Madrid: 1854), El Último figurín (Madrid: 1871-1872), La Nueva Caprichosa (La Habana: 1906-1912), El Semanario del Pacífico (Lima) y El Continente Americano (México).

${ }^{2}$ Otros ejemplos de publicaciones periódicas que ofrecían información sobre los salones literarios eran : El Ángel del Hogar: Revista semanal de literatura, educación, modas, teatros y salones editado por María del Pilar Sinués de Marco y el Nuevo teatro crítico editado por Emilia Pardo Bazán.

${ }^{3}$ Emilia Serrano de Wilson, La Caprichosa, January 1858, p.3: “¿Y qué diremos de los bonitos sombreros que al recorrer los salones de Alexandrine hemos tenido ocasión de admirar?". 


\section{BIBLIOGRAFÍA}

Alarcón Sierra, Rafael, and Manuel Machado, eds. Impresiones. El modernismo. Artículos, crónicas y reseñas 1899-1909. Valencia: Pre-Textos, 2000.

Carmona González, María. Escritoras andaluzas en la prensa de Andalucía del siglo XIX. Cádiz: Universidad de Cádiz, Instituto Andaluz de la Mujer, 1999.

Correa Ramón, Amelina. "El sorprendente caso de la granadina Emilia Serrano, o una escritora aventurera del XIX.” Renacimiento, 31/34 (2002): 64-66.

Ezama Gil, Ángeles. "Las periodistas españolas pintadas por sí mismas.” Arbor: Ciencia, pensamiento y cultura, 190 (767): a136 (2014): 1-12.

Fernández, Pura, and Marie-Linda Ortega, eds. La mujer de letras o la letraherida: discurso y representaciones sobre la mujer escritora en el siglo XIX. Madrid: Consejo Superior de Investigaciones Científicas, 2008.

Heyden-Rynsch, Verena von der. Los salones europeos. Las cimas de una cultura femenina desaparecida. Traducido por José Luis Gil Aristu, Barcelona: Península, 1998.

Martin-Fugier, Anne. Les Salons de la IIIe République. Paris: Perrin, 2003.

Pardo Bazán, Emilia. La vida contemporánea. Barcelona: Antonio López, 1896.

Pilar Sinués de Marco, María del. El Ángel del Hogar. Biblioteca Nacional de España: Hemeroteca Digital, December 1865.

Rabaté, Colette. ¿Eva o María? Ser mujer en la época Isabelina (1833-1868). Salamanca: Ediciones Universidad de Salamanca, 2007.

Sánchez Llama, Iñigo. Galería de escritoras isabelinas: la prensa periódica entre 1833 y 1895. Madrid: Cátedra, 2000.

Serrano de Wilson, Emilia. La Caprichosa. Biblioteca Nacional de España: Hemeroteca Digital, Febrero 1858.

Serrano de Wilson, Emilia. América y sus mujeres. Barcelona: Fidel Giro, 1890.

Serrano de Wilson, Emilia. Las perlas del corazón. Barcelona/Buenos Aires: Maucci Hermanos, 1911.

Sherman Swing, Elizabeth, and François Orivel and Jürgen Schriewer. Problems and Prospects in European Education. Westport: Praeger, 2000.

Simón Palmer, María del Carmen. Revistas femeninas madrileñas. Madrid: Artes Gráficas Municipales, 1993. 
